Article

\title{
Novel Aminoacridine Sensors Based on Molecularly Imprinted Hybrid Polymeric Membranes for Static and Hydrodynamic Drug Quality Control Monitoring
}

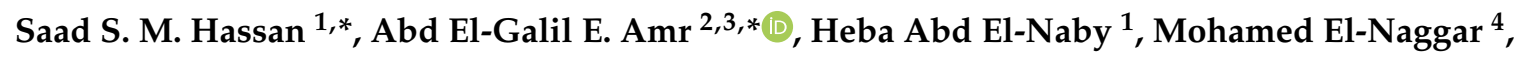 \\ Ayman H. Kamel ${ }^{1, *(D)}$ and Nagy M. Khalifa ${ }^{2,3}$ \\ 1 Department of Chemistry, Faculty of Science, Ain Shams University, Abbasia 11566, Cairo, Egypt; \\ hoba_science@hotmail.com \\ 2 Pharmaceutical Chemistry Department, Drug Exploration \& Development Chair (DEDC), \\ College of Pharmacy, King Saud University, Riyadh 11451, Saudi Arabia; nkhalifa.c@ksu.edu.sa \\ 3 Applied Organic Chemistry Department, National Research Center, Dokki 12622, Giza, Egypt \\ 4 Chemistry Department, Faculty of Sciences, University of Sharjah, Sharjah 27272, UAE; \\ m5elnaggar@yahoo.com \\ * Correspondence: saadsmhassan@sci.asu.edu.eg (S.S.M.H.); aamr@ksu.edu.sa (A.E.-G.E.A.); \\ ahkamel76@sci.asu.edu.eg (A.H.K.); Tel.: +966-565-148-750 (A.E.-G.E.A.)
}

Received: 9 September 2019; Accepted: 10 October 2019; Published: 12 October 2019

\begin{abstract}
Novel biomimetic potentiometric ion-selective electrodes (ISEs) were fabricated and designed for the assessment of aminoacridine (ACR) based on newly synthesized imprinted polymer (MIP) membranes. Thermal polymerization of methacrylic acid (MAA) or acrylamide (AM) as function monomer, aminoacridine as a template and ethylene glycol dimethacrylate (EGDMA) as across-linker, were utilized to give the molecular recognition part. The membranes of sensors I andII consist of MIP based MAA and AM, respectively, dispersed in a poly(vinyl chloride) membrane plasticized with dioctyl phthalate (DOP) in the ratio of $3.0 \mathrm{wt} \%, 32.2 \mathrm{wt} \%$ and $64.8 \mathrm{wt} \%$, respectively. Sensors III and IV were similarly prepared with added $1.0 \mathrm{wt} \%$ tetraphenyl borate $\left(\mathrm{TPB}^{-}\right)$as an anionic discriminator. Sensors I and II exhibited near-Nernstian potential response to $\mathrm{ACR}^{+}$with slopes of $51.2 \pm 1.3$ and $50.5 \pm 1.4 \mathrm{mV} /$ decade in a $0.01 \mathrm{M}$ phosphate buffer of $\mathrm{pH} 6.0$. The linear response coversthe concentration range of $5.2 \times 10^{-6}$ to $1.0 \times 10^{-3} \mathrm{M}$ with a detection limit of 0.05 and $0.17 \mu \mathrm{g} / \mathrm{mL}$ for sensors I and II, respectively. The performance characteristics of these sensors were evaluated under static and hydrodynamic mode of operations. They were used for quality control assessment of aminoacridine in some pharmaceutical preparations and biological samples.
\end{abstract}

Keywords: potentiometric sensors; aminoacridine; quality control; flow injection analysis (FIA)

\section{Introduction}

Acridine and its derivatives are antimicrobial agents, effective against a wide range of microorganisms. Aminoacridine is commonly used in the treatment of infections of vaginal candidacies, trichomonavaginitis, haemophilia, moniliasis, and as prophylactic agent in various gynaecological procedures [1]. 9-Aminoacridine is the most active among all aminoacridine derivatives due to its higher basicity. It is used also in the treatment of tinea versicolor and mastitis [2]. It is also used as a safe and effective irrigant in dentistry. Available literature confirms that it is a potent antimicrobial agent, effective against a wide range of microorganisms commonly found in septic wounds and causing minimal tissue irritation [3]. In addition, it is used in dentistry for surgical root canal irrigation and as antiseptic in management of maxillofacial abscesses [4]. However, few methods are available in the literature for the determination of acridine and its derivatives. Chemilumiscence measurement after 
oxidation with permanganate and optical solvatochromic method has been suggested [5]. Non-aqueous potentiometric titration with perchloric acid or titration with chlorosulphonic and location of the end point by potentiometry and photometry has been described [6,7]. Adsorptive stripping voltammetry at a static mercury dropping electrode has been used for acridine assessment [8]. Reversed phase HPLC, TLC and GLC have been utilized for separation and quantitation of aminoacridine $[9,10]$ and spectrophotometric and fluorimetric methods for aminoacridine determination [11,12]. Most of these methods suffer from lack of selectivity and sensitivity or involved several time consuming manipulation steps. Although potentiometric polymeric membrane ion selective sensors find wide applications in environmental, clinical and pharmaceutical analysis due to simplicity, accuracy and selectivity, no single sensor has been described for determination of acridine compounds.

Molecular imprinting technology had increased interest in the recent years [13]. The importance of this technique was reflected in several reviews [14-17]. They discussed the application of MIPs in different fields such as solid phase extraction, chromatographic separations or as drug delivery systems [14-17]. Regarding chemical sensing, Haupt and Mosbach [15], presented a review about MIPs and their use in biomimetic sensors. On the other hand, molecularly imprinted technology (MIT) is one of the most promising methodologies for the conjunction with potentiometric sensors. They have been successfully developed for the assessment of various analytes [18-22]. In this respect, achievement of improved selectivity may be done by means of using MIP as a sensing element. In addition, they have a pre-defined specific cavities designated for the desired analyte, stable to wide $\mathrm{pH}$ range, organic solvents and temperature variations. These features provide for high flexibility in analytical and bio-analytical methods development [23-26].

In this work, novel molecularly imprinted 9-aminoacridine (ACR) polymers were prepared, characterized, incorporated in a poly(vinyl chloride) matrix membranes and utilized in conjunction with a potentiometric transduction for selective determination of low concentration levels of 9-aminoacridine in drug formulation and biological matrices.

\section{Materials and Methods}

\subsection{Apparatus and Reagents}

The potential measurements were conducted at $25 \pm 1{ }^{\circ} \mathrm{C}$ with an Orion (Cambridge, MA, USA) Model $720 / \mathrm{SA} \mathrm{pH} / \mathrm{mV}$ meter using molecularly imprinted aminoacridine membrane sensor in conjunction with an Orion $\mathrm{Ag} / \mathrm{AgCl}$ double-junction reference electrode (Model 90-20) filled with $10 \%(\mathrm{w} / \mathrm{v}) \mathrm{KNO}_{3}$. All $\mathrm{pH}$ measurements and solution $\mathrm{pH}$ adjustments were made with a combination Ross glass electrode (Orion 81-02).Continuous analysis was performed using a flow injection manifold consisted of a two-channel peristaltic pump (Ismatech Ms-REGLO), polyethylene tubing $(0.71 \mathrm{~mm}$ i.d.) and an Omnifit injection valve (Omnifit, Cambridge, UK) with a sample loop of $100 \mu \mathrm{L}$ volume. The potential signals were recorded using data acquisition (eight-channel electrode-computer interface (Nico- 2000 Ltd., London, UK) controlled by Nico-2000 software).

All chemicals were of analytical grade or the highest purity available. 9-Aminoacridine (ACR) from National Authority for Control and Pharmaceutical Research (Egypt), high molecular weight poly (vinyl chloride) (PVC), Dioctylphthalate (DOP) acrylamide (AM), methacrylic acid (MAA) and ethylene glycol dimethacrylate (EGDMA) were used as received from Fluka (Ronkonoma, NY, USA). Phosphoric acid, and tetrahydrofurane (THF), were purchased from Sigma (St. Louis, MO).Benzoyl peroxide (BPO) from Riedel-deHaen. Methanol, acetic acid and acetonitril were bought from Merck. All measurements were done in $1.0 \times 10^{-2} \mathrm{M}$ phosphate buffer at $\mathrm{pH} 6.0$. A stock solution of $1.0 \times 10^{-2} \mathrm{M}$ ACR was prepared in distilled water. Working solutions $\left(1.0 \times 10^{-3}-1.0 \times 10^{-6} \mathrm{M}\right)$ were prepared by accurate dilutions and stored in brown bottles. 


\subsection{Synthesis of Molecularly Imprinted Polymers}

MIP beads were prepared through the non-covalent approach [27]. Briefly, the template (ACR, $0.4 \mathrm{mmol}$ ), methacrylic acid or acrylamide (MAA or AM, $5 \mathrm{mmol}$ ), ethylene glycol dimethacrylate (EGDMA, $24 \mathrm{mmol}$ ) and benzoylperoxide (BPO, $50 \mathrm{mg}$ ) were dissolved in acetonitril (AN, $10 \mathrm{~mL}$ ) in a $50 \mathrm{~mL}$ flask. The mixture was sonicated for $5 \mathrm{~min}$ to achieve homogeneity then degassed by $\mathrm{N}_{2}$ for $10 \mathrm{~min}$. The polymerization was performed at $70^{\circ} \mathrm{C}$ in a water bath for $18 \mathrm{~h}$. After polymerization, the template was removed by batch-mode solvent extraction using methanol/acetic acid (8:2) and methanol. The resulting polymer was dried in vacuum overnight at room temperature. The non-imprinted polymer (NIP) particles were prepared by the same procedure in absence of the template.

\subsection{Membrane Sensors and Potential Measurements}

The membranes of the sensors used for batch measurement of the drug were prepared by dissolving $570 \mathrm{mg}$ of the components [MIP or NIP $(30 \mathrm{mg})$, PVC $(190 \mathrm{mg})$, and DOP $(350 \mathrm{mg})]$ in $5 \mathrm{~mL}$ THF in a ( $5 \mathrm{~cm}$ diameter) glass ring. The membranes of sensors (I) and (II) consist of MIP based MAA and AM, respectively. Sensors (III) and (IV) were similarly prepared with added $1.0 \mathrm{wt} \% \mathrm{TPB}$ as an anionic discriminator.Membranes containing NIP based MAA and AM were also prepared to make sensors (V) and (VI), respectively. All membrane solutions were left to stand overnight at room temperature to evaporate the solvent slowly. The resulting membrane was peeled off from the glass ring and discs of $9 \mathrm{~mm}$ i.d. were cut out and glued onto a 7-mm i.d PVC body using THF. The tube was filled with $10^{-2} \mathrm{M}$ aminoacridinium hydrochloride as internal solution and $3 \mathrm{~mm}$ diameter $\mathrm{Ag} / \mathrm{AgCl}$ coated wire was used as an internal reference electrode. A $1.0 \times 10^{-2} \mathrm{M}$ aqueous ACR solution was used as a conditioning solution for sensors, and stored in the same solution when not in use.

The potential measurements under a static mode of operation were recorded after immersion of the sensors in conjunction with double-junction $\mathrm{Ag} / \mathrm{AgCl}$ reference electrode in solutions containing a $1.0 \times 10^{-2}-1.0 \times 10^{-6} \mathrm{M}$ of ACR. All solutions were adjusted at $\mathrm{pH} 6.0$ with $0.01 \mathrm{M}$ phosphate buffer. The potential readings were recorded after stabilization to $\pm 0.5 \mathrm{mV}$ and the EMF was plotted as a function of the logarithm (ACR) concentration. The life time of the membranes was 2 months.

The detector used for continuous drug analysis was prepared as described previously [28]. The membrane cocktail was deposited; using a micro-dropper, three to four times in a smallhole $(3 \mathrm{~mm}$ wide $\times 5 \mathrm{~mm}$ length) made in the middle of a $15 \mathrm{~cm}$ Tygon tube ( 0.071 i.d.). The tube was inserted and sealed with Araldite in a $100 \mu \mathrm{L}$ pipette tip $(7 \mathrm{~cm}$ long, $0.4 \mathrm{~cm}$ diameter). The formed membrane sensor was inserted into the flow injection system as schematically shown in Figure 1. The end of the tube was placed in a Petri dish where a double junction $\mathrm{Ag} / \mathrm{AgCl}$ reference electrode was placed down-stream from the indicator sensor just before the solution went to waste. The sample loop (100 $\mu \mathrm{L})$ of the injection valve was filled and the valve was rotated to allow the sample to be carried out by $0.01 \mathrm{M}$ phosphate buffer stream of $\mathrm{pH} 6.0$ to the flow-through cell. The potential signals were recorded using data acquisition (eight-channel electrode-computer interface (Nico-2000 Ltd., London, UK) controlled by Nico-2000 software). Each sample was measured in triplicate runs and the average peak height was recorded and compared with a calibration plot under the same condition.

\subsection{Binding Capacity of Aminoacridine Molecularly Imprinted Polymer}

All polymers were analyzed for binding template using equilibrium binding experiments [29]. This was carried out by placing $(30 \mathrm{mg}$ ) of MIP or NIP particles in contact with $10 \mathrm{~mL}$ of ACR solutions ranging from $0.01-10 \mathrm{mM}$. The solutions were incubated overnight for a static equilibrium at room temperature and centrifuged at $6000 \mathrm{rpm}$ for $15 \mathrm{~min}$. The solid phase was then separated and the free ACR concentration was measured by sensor (II). 


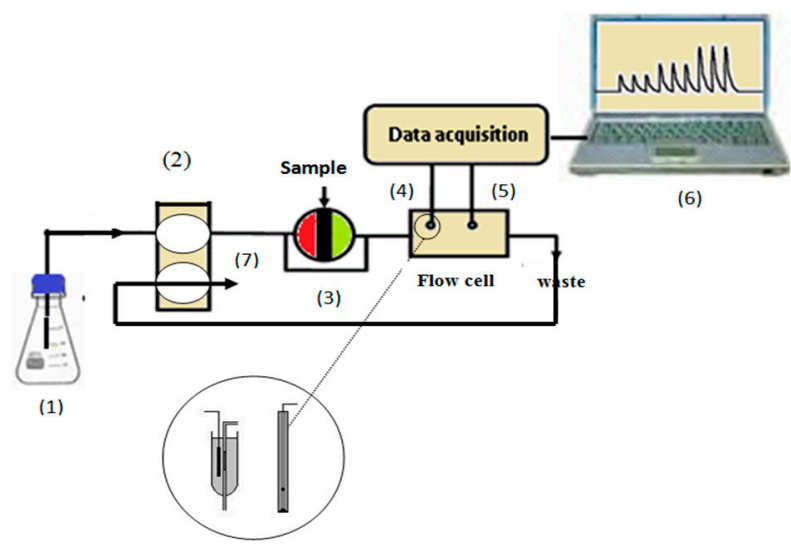

Figure 1. Schematic diagram of the flow injection system. (1) $10^{-2} \mathrm{M}$ phosphate buffer carrier; (2) peristaltic pump; (3) loop sample $100 \mu \mathrm{L}$; (4) working electrode; (5) reference electrode; (6) laptop;

(7) waste; conditions: flow rate $3.5 \mathrm{~mL} / \mathrm{min}$.

\subsection{Selectivity Towards Other Cations}

The potentiometric selectivity coefficients $\left(K^{\text {pot }}{ }_{i, j}\right)$ of the proposed ACR sensors towards different cationic species (j) were measured using the fixed interference method (FIM) [30]. A $1.0 \mathrm{~mL}$ aliquot of $1 \times 10^{-2} \mathrm{M}$ of the interfering ion (j) was transferred into a $50 \mathrm{~mL}$ beaker containing $9.0 \mathrm{~mL}$ of phosphate buffer of $\mathrm{pH} 6.0$ and the sensor in conjunction with a double junction $\mathrm{Ag} / \mathrm{AgCl}$ reference electrode was immersed in the solution and calibrated with ACR stock solution. The selectivity coefficient was measured and calculated from the rearranged Nicolsky equation [30]:

$$
\log K_{i, j}^{\text {pot }}=-\log a_{j}^{\left(Z_{i} / Z_{j}\right)}+\log a_{i}
$$

where $a_{i}=a_{j}=10^{-3} \mathrm{M}$ are the activities and $z_{i}$ and $z_{j}$ are the charges of ACR and the interfering ion respectively. The selectivity of sensors (III) and (IV) where tetraphenyl borate (TPB) was used as cationic additive was also studied.

\subsection{Determination of ACR in Biological Fluids}

To test the applicability of the sensors in more complicated matrices, known addition (spiking) technique was followed and the concentration of ACR in different plasma and urine samples was measured under both static and hydrodynamic mode of operation. A $10 \mathrm{~mL}$ aliquot of plasma or urine sample was transferred, without removal of any particulate matter, to a $100 \mathrm{~mL}$ measuring flask and diluted to the mark with $0.01 \mathrm{M}$ phosphate buffer solution of $\mathrm{pH}$ 6.0. A $1.0 \mathrm{~mL}$ aliquot was transferred to $25 \mathrm{~mL}$ beaker containing $9 \mathrm{~mL}$ buffer solution. Portions $(1.0 \mathrm{~mL})$ of standards $1.0 \times 10^{-4}, 5.0 \times 10^{-4}$, $1.0 \times 10^{-3}$ and $1.0 \times 10^{-2} \mathrm{M}$ ACR representing samples $\left(\mathrm{S}_{1}, \mathrm{~S}_{2}, \mathrm{~S}_{3}, \mathrm{~S}_{4}\right)$ were added to the buffered urine solution. Portions $(1.0 \mathrm{~mL})$ of the standard $1.0 \times 10^{-4}, 1.0 \times 10^{-3}$ and $1.0 \times 10^{-2} \mathrm{M}$ ACR representing samples $\left(\mathrm{S}_{5}, \mathrm{~S}_{6}, \mathrm{~S}_{7}\right)$ were added to the buffered plasma solution. Each of these solutions was thoroughly mixed and the aminoacridine sensor in conjunction with the reference electrode was immersed in the solution. The potential readings were recorded after reaching the equilibrium response (10-20 s).

\subsection{Determination of $A C R$ in Pharmaceutical Samples}

An accurately weighed $40 \mathrm{~g}$ of Septgel drug containing $0.01 / 20(w / w)$ aminoacridine was transferred into a $100 \mathrm{~mL}$ volumetric flask. $0.01 \mathrm{M}$ phosphate buffer of $\mathrm{pH} 6$ was added to dissolve and dilute the sample $\left(\mathrm{S}_{8}\right)$ to the flask mark. The solution was measured as described above and the potential reading was compared with a calibration plot under similar conditions under both static and hydrodynamic modes of operation. 


\section{Results and Discussions}

\subsection{Characterization of the MIP Particles}

As artificial mimetic, MIPs have proven to be excellent receptors for the selective recognition of organic targets in chemical sensors [11,12,18-20,22-24]. In this work we explore for the first time the feasibility for fabricating a potentiometric sensor based on MIP in the polymeric membrane as a selective receptor for 9-aminoacridine. In the polymerization step, MAA and AM were tested as functional monomers in presence of EGDMA as a cross-linker. The carboxylic group (COOH) of MAA or amide group $\left(-\mathrm{CONH}_{2}\right)$ of $\mathrm{AM}$ can interact through strong hydrogen bonding with the amino $\left(-\mathrm{NH}_{2}\right)$ and basic nitrogen in the pyridine ring. In addition, contribution of $\pi$-interactions from the aromatic moiety of the template towards the electron deficient centers in the polymer structure is considered. Formation of aminoacridine MIPs were confirmed by the Fourier-transform-infrared spectroscopy (FT-IR), and characterized by using scanning electron microscopy (SEM).

The SEM images of the prepared polymeric materials were shown in Figure 2. The different surface structures can come from different physical properties during polymerization. The presence of the template during polymerization can cause different particles even if there's no imprinting effect.All the beads of MIP have an irregular and rough surface due to the high amount of the cross-linker added during the polymerization process and to the pores formed during the imprinting of ACR on the polymers. For NIP beads, they have more smooth and uniform shapes than MIPs because ACR wasn't entered in the polymerization process. The diameter distribution of the micro-beads was 2.1-2.4 $\mu \mathrm{m}$ and 1.23-1.54 $\mu \mathrm{m}$ for MIP and NIP particles, respectively. This difference between the size of MIP and NIP particles can be attributed to the imprinting effect.

The FT-IR spectra of MIPs particles confirm the imprinting process through the absence and presence of ACR on the surface of both washed or non-washed polymer particles, respectively Figures 3 and 4. Nicolet ${ }^{\mathrm{TM}}$ iS50 (ATR-FTIR) Spectrometer in a spectral range of $4000-500 \mathrm{~cm}^{-1}$ was used. From the FT-IR analysis, it can be seen that ACR is characterized by the presence of bands due to $\gamma_{\mathrm{N}-\mathrm{H}}$ (stretching) at 3421, $3342 \mathrm{~cm}^{-1}, \gamma_{\mathrm{N}-\mathrm{H}}$ (bending) at $1590 \mathrm{~cm}^{-1}, \gamma_{\mathrm{C}-\mathrm{H}}$ (stretching, aromatic) at 2914, $2855 \mathrm{~cm}^{-1}$, sharp and strong stretching $\gamma_{\mathrm{C}=\mathrm{C}}$ (stretching) at $1660 \mathrm{~cm}^{-1}$, and $\gamma_{\mathrm{C}-\mathrm{N}}$ (stretching) in the aromatic ring and C-N at position (9) at 1268 and $1161 \mathrm{~cm}^{-1}$, respectively. The FT-IR spectrum of non-washed MIP based on MAA as a functional monomer showed O-H stretch due to methacrylic monomer at $3444 \mathrm{~cm}^{-1}$. The band due to $\gamma_{\mathrm{N}-\mathrm{H}}$ (bending) at $1590 \mathrm{~cm}^{-1}$ was disappeared and that due to $\gamma_{\mathrm{C}-\mathrm{N}}$ band at $1162 \mathrm{~cm}^{-1}$ was broadened. This confirms that the imprinted process proceeded through the hydrogen bond between the amino group of the template and the amide group in MAA monomer. In addition, there was a shift of $\gamma_{\mathrm{C}=\mathrm{O}}$ (stretching) of the amide group from the cross linker to $1733 \mathrm{~cm}^{-1}$ and that $\gamma_{\mathrm{C}=\mathrm{O}}$ (stretching) of the amide group of the monomer to $1636 \mathrm{~cm}^{-1}$. The two peaks at about 1727 and $1167 \mathrm{~cm}^{-1}$, corresponding to $-\mathrm{C}=\mathrm{O}$ or $-\mathrm{C}-\mathrm{O}$ stretches, respectively, are common in all spectra because of the EGDMA cross-linker used. For NIP/MAA/ACR, it was characterized by $\gamma_{\mathrm{N}-\mathrm{H}}$ (stretching) band at $3580 \mathrm{~cm}^{-1}$, strong and sharp $\gamma_{\mathrm{C}-\mathrm{O}}$ (stretching) band at $1167 \mathrm{~cm}^{-1}$ and $\gamma_{\mathrm{C}-\mathrm{H}}$ (stretching) band at $2973 \mathrm{~cm}^{-1}$ that fairly agreed with those obtained for MIP/MAA/ACR after template removal. The FT-IR spectrum of non-washed MIP based on AM as a functional monomer showed that, the $\gamma_{\mathrm{N}-\mathrm{H}}$ (stretching) was shifted to $3446 \mathrm{~cm}^{-1}$ with more broadening, disappearance of $\gamma_{\mathrm{N}-\mathrm{H}}$ (bending) located at $1590 \mathrm{~cm}^{-1}$ and broadening in $\gamma_{\mathrm{C}-\mathrm{N}}$ band located at $1161 \mathrm{~cm}^{-1}$. This confirms that the imprinted process proceeded through the hydrogen bond between amino group in the template and the amide group in AM monomer. In addition, there was a shift for $\gamma_{\mathrm{C}=\mathrm{O}}$ (stretching) of the amide group from the cross linker to $1733 \mathrm{~cm}^{-1}$ and that $\gamma_{\mathrm{C}=\mathrm{O}}$ (stretching) of the amide group from the monomer shifted to $1636 \mathrm{~cm}^{-1}$. The two peaks at about 1732 and $1158 \mathrm{~cm}^{-1}$, corresponding to-C=O or -C-O stretches, respectively, are common in all spectra because of the EGDMA cross-linker used. For NIP/AM/ACR, it was characterized by $\gamma_{\mathrm{N}-\mathrm{H}}$ (stretching) band at $3429 \mathrm{~cm}^{-1}$, strong and sharp $\gamma_{\mathrm{C}-\mathrm{O}}$ (stretching) band at $1158 \mathrm{~cm}^{-1}$ and $\gamma_{\mathrm{C}-\mathrm{H}}$ (stretching) band at $2957 \mathrm{~cm}^{-1}$. These bands are similar to 
those obtained with MIP/AM/ACR after template removal. The coincidence of the spectrum of NIP beads and that of washed MIPs, confirms the successful removal of the template after washing.

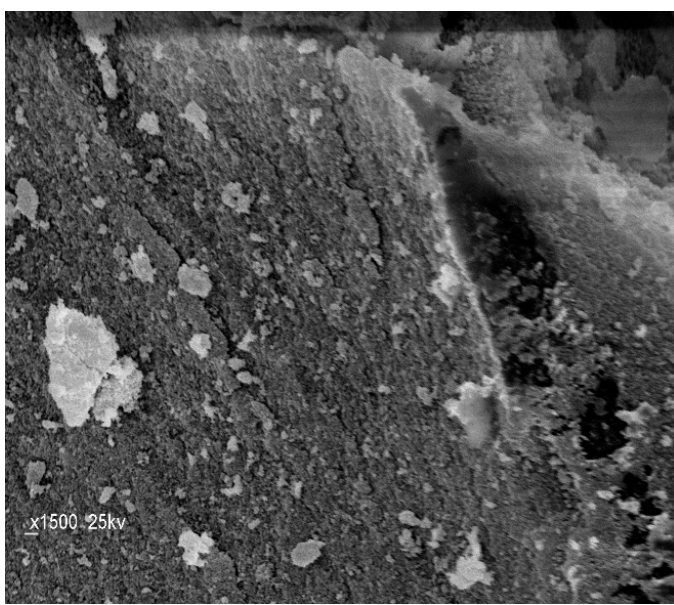

(A)

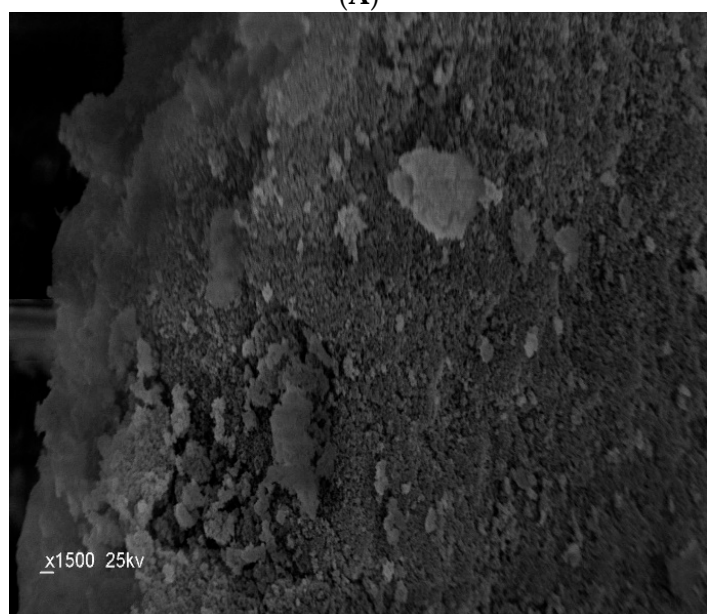

(C)

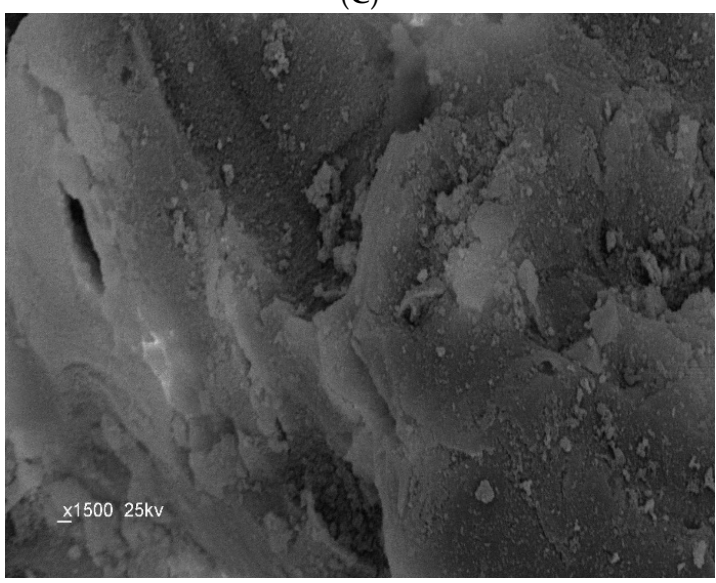

(E)

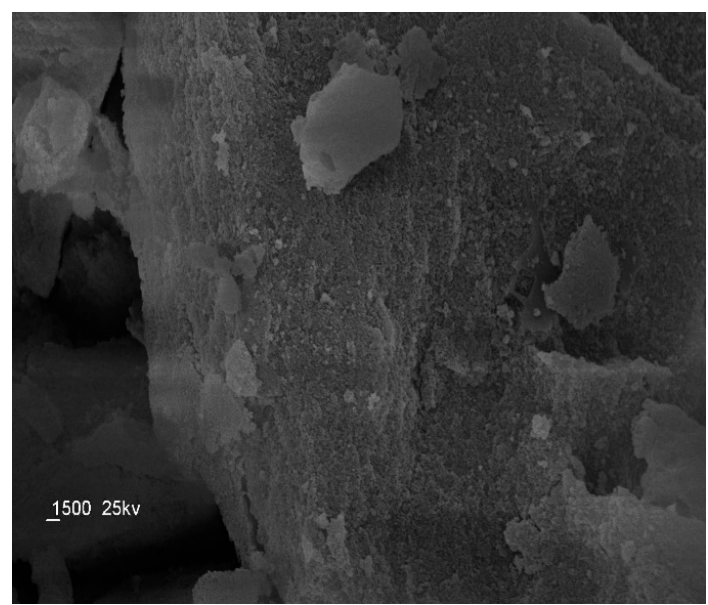

(B)

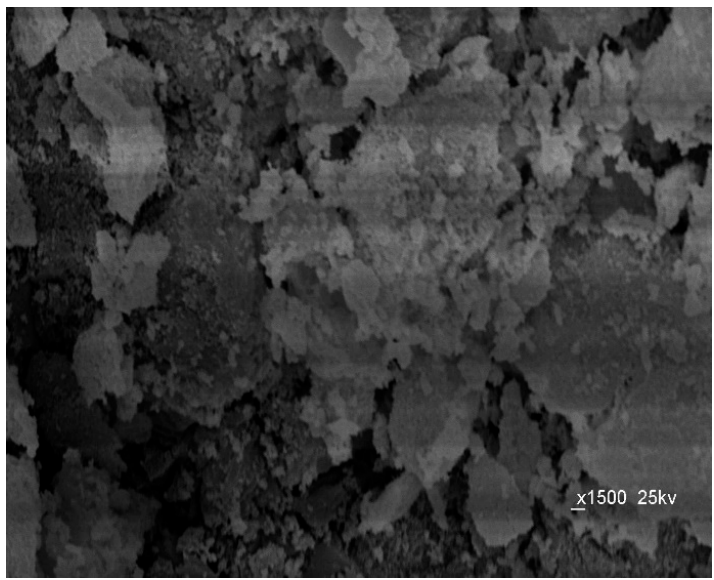

(D)

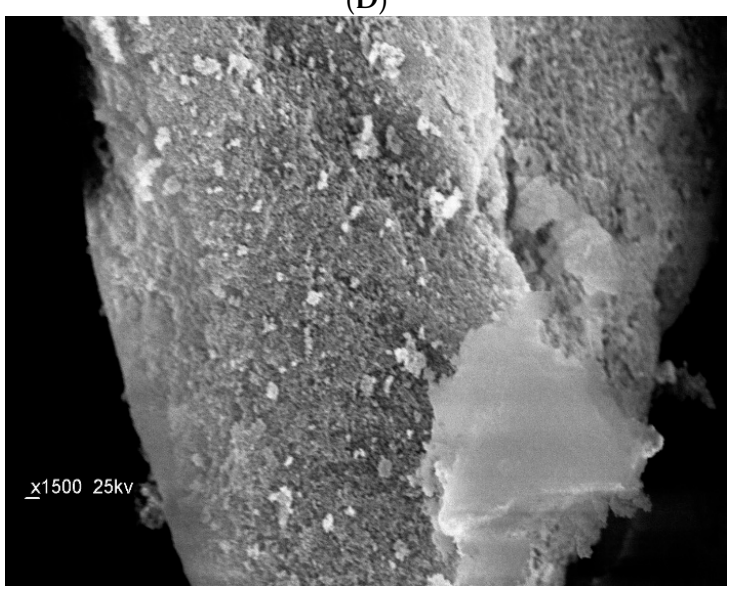

(F)

Figure 2. SEM images of the obtained MIP and NIP beads: (A) non-washed MAA/MIP; (B) washed MAA/MIP; (C) MAA/NIP; (D) non-washed AM/MIP; (E) washed AM/MIP, and; (F) AM/NIP. 


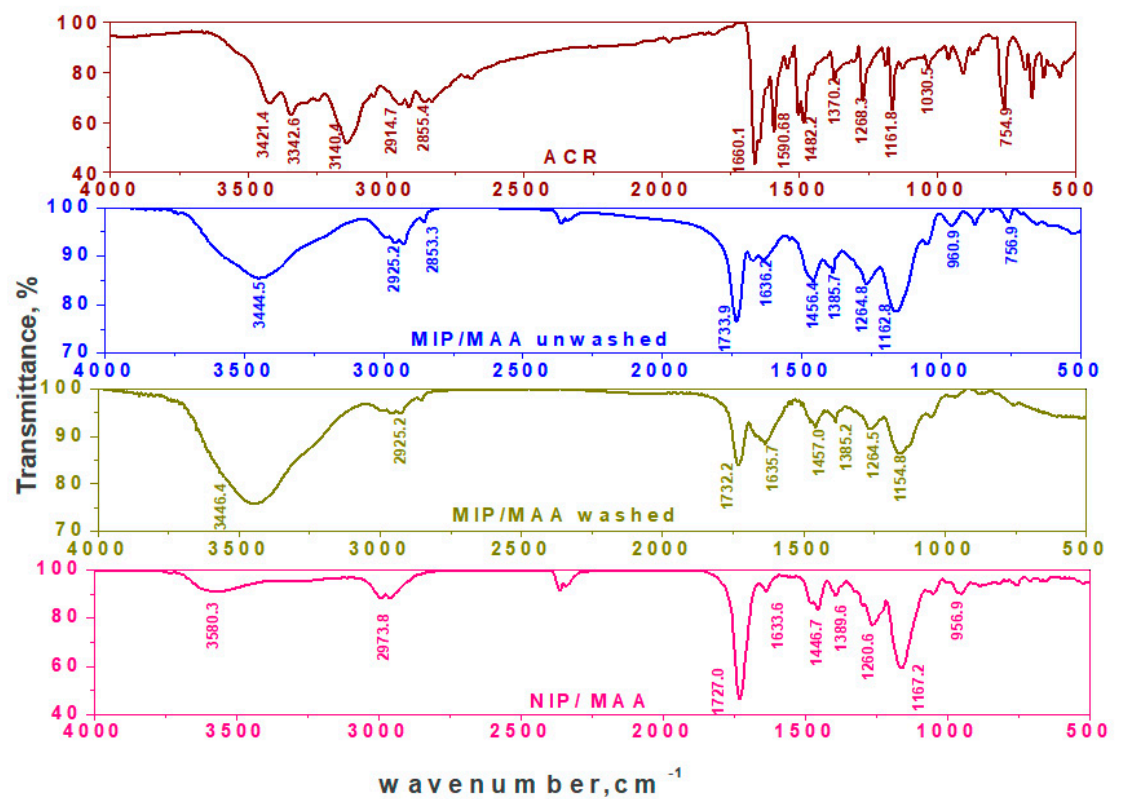

Figure 3. FTIR spectra of ACR, MIP with MAA monomer and NIP.

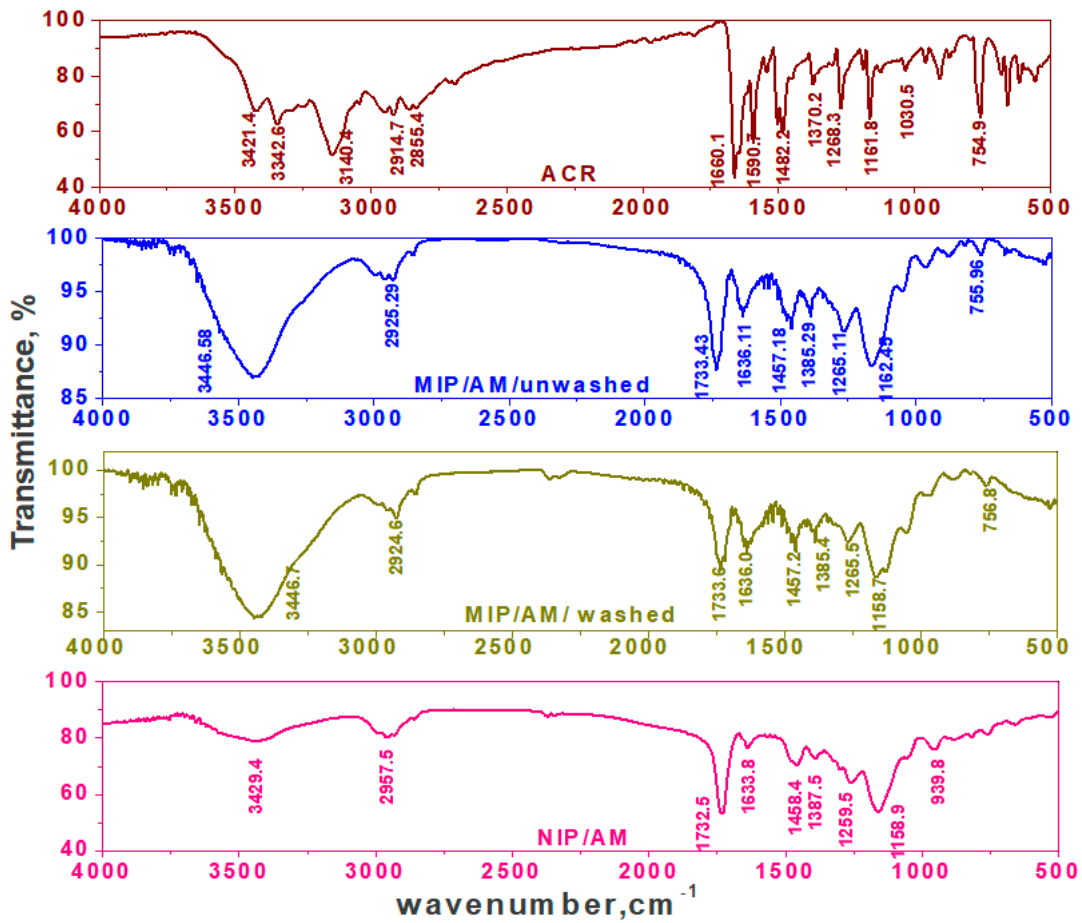

Figure 4. FTIR spectra of ACR, MIP with AM monomer and NIP.

\subsection{Binding Capacity of MIPs and Scatchard Analysis}

The capacity of MIPs up take ACR was investigated using equilibrium binding experiments [29]. The mode of binding, site distributions in the interaction and adsorption isotherms were examined by using a fixed amount ( $30 \mathrm{mg}$ ) of MIP or NIP beads and varying initial concentrations ( 0.01 to $10 \mathrm{mM})$ of the ACR. After soaking for $24 \mathrm{~h}$ at ambient temperature the capacity of MIPs was calculated according to following equation:

$$
Q=\frac{\text { mmol }(\text { ACRbound })}{g(\text { MIP })}=\frac{\left(C_{i}-C_{f}\right) V_{s} \times 1000}{M_{M I P}}
$$


where $Q$ is binding capacity of MIP or NIP $\left(\mathrm{mmol} \mathrm{g}^{-1}\right), C_{i}$ the initial ACR concentration $\left(\mathrm{mmol} \mathrm{mL}^{-1}\right)$, $C_{f}$ the final ACR concentration $\left(\mathrm{mmol} \mathrm{mL}^{-1}\right), V_{s}$ the volume of solution tested $(\mathrm{mL})$ and $M_{M I P}$ the mass of dried polymer (mg). The adsorption isotherms for MIPs were shown in Figure 5A,C. It can be seen from the curves that the binding amounts for MIP and NIP polymers increase with increasing the amount of ACR concentration. At the concentration of $5 \mathrm{mM} \mathrm{ACR}$, the bounded amount of ACR by the imprinted polymer is 273 and $223.3 \mu \mathrm{mol} \mathrm{g}^{-1}$ for MIP/AM and MIP/MAA, respectively. For non-imprinted polymers at the same ACR concentration, the bounded amount by the polymer is 63.3 and $33.4 \mu \mathrm{mol} \mathrm{g}^{-1}$ for NIP/AM and NIP/MAA, respectively.

The Scatchard Model was often used to evaluate the binding characteristics of the imprinted polymers through the following equation [31]:

$$
[Q] /\left[C_{\text {free }}\right]=\left(\left[Q_{\max }\right]-[Q]\right) / K_{d}
$$

where $\left[C_{\text {free }}\right]$ is the remaining concentration of the substrate in the supernatant, $\left[Q_{\max }\right]$ is the maximum binding capacity of the binding site and $K_{d}$ is the equilibrium dissociation constant. $[Q] /\left[C_{f r e e}\right]$ was plotted versus $Q$ as shown in Figure 5B,D. These figures illustrate that the binding sites of MIP beads for ACR were heterogeneous with linear relationships which indicate the presence of two classes of binding sites with different affinities in the range of the different concentrations. The equilibrium dissociation constants $K_{d 1}, K_{d 2}$ and the apparent maximum amount $Q_{\max 1}, Q_{\max 2}$ for the higher and lower affinity binding sites are summarized in Table 1 . These data showed that MIP/AM has a higher binding affinity and maximum binding capacity towards ACR than MIP/MAA.
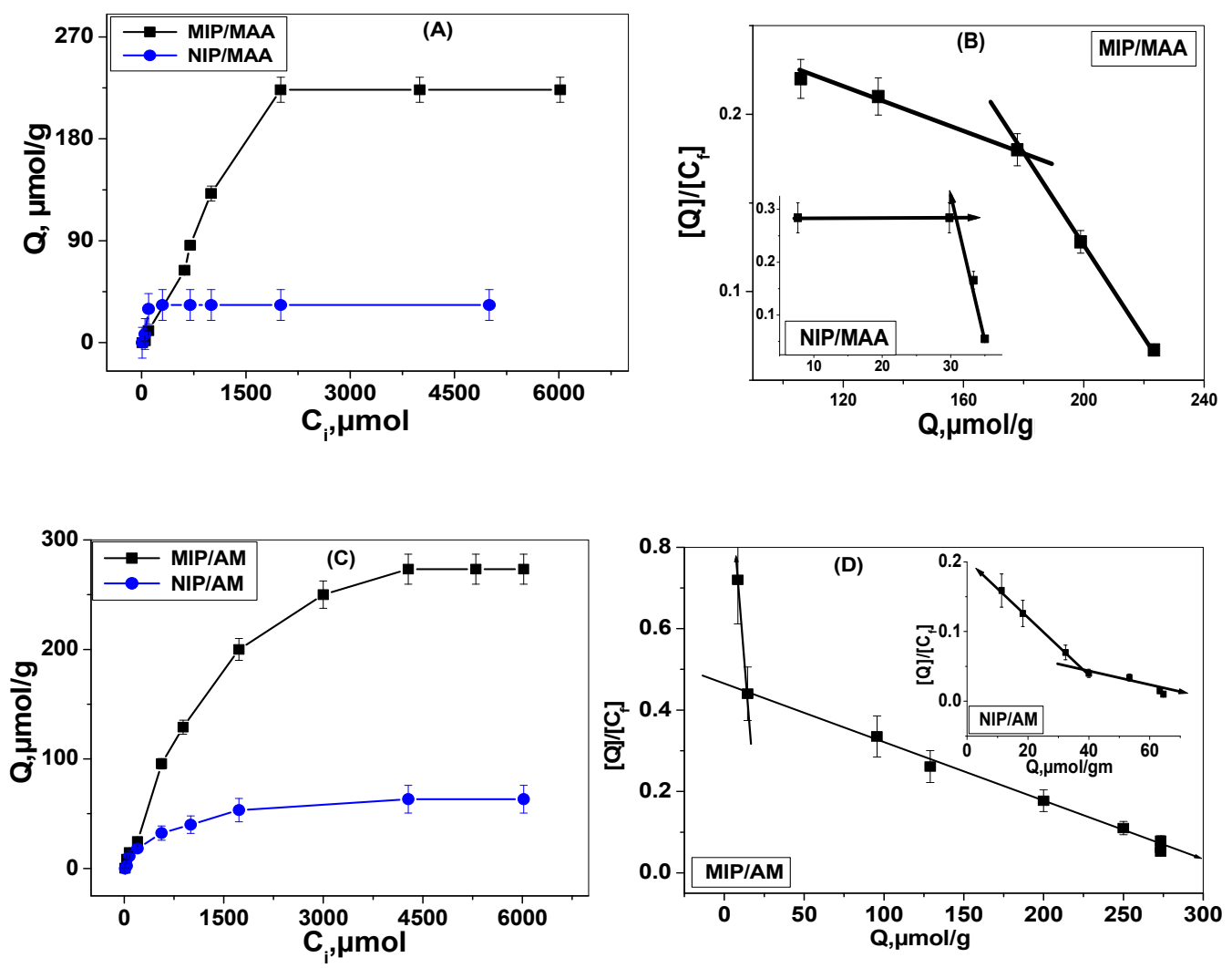

Figure 5. Binding isotherm and Scatchard analysis for (A) MIP/MAA, (B) NIP/MAA, (C) MIP/AM and (D) NIP/AM polymers, Conditions: $30.0 \mathrm{mg}$ of the respective polymer; $t=25^{\circ} \mathrm{C} ; \mathrm{V}=10.0 \mathrm{~mL}$; binding time: $24 \mathrm{~h}$. 
Table 1. Scatchard analysis of MIPs and NIPs.

\begin{tabular}{ccccc}
\hline Scatchard Parameters & MIP/MAA/ACR & NIP/MAA/ACR & MIP/AM/ACR & NIP/AM/ACR \\
\hline $\mathrm{K}_{\mathrm{d} 1}, \mu \mathrm{M}$ & 1764.91 & - & 22.14 & 242.72 \\
$\mathrm{Q}_{\max 1}, \mu \mathrm{mol} / \mathrm{g}$ & 497.35 & - & 24.37 & 49.48 \\
$\mathrm{~K}_{\mathrm{d} 2}, \mu \mathrm{M}$ & 401.6 & 15.04 & 724.63 & 487.8 \\
$\mathrm{Q}_{\max 2}, \mu \mathrm{mol} / \mathrm{g}$ & 250.07 & 35.82 & 329.71 & 69.87 \\
\hline
\end{tabular}

\subsection{Sensors Performances}

The electrochemical characteristics of ACR membrane-based sensors were evaluated according to IUPAC recommendations [32]. Their general analytical features are presented in Table 2. It should be noted that Polymeric membrane sensor have the advantages of offering the possibility of controlling electrode characteristics such as hydrophobic/hydrophilic character, permeability and film thickness, all of which are essential for obtaining good sensor performance. The imprinting polymer is able to rebind again to its imprinted cavity after washing out the template, thus acting as a recognition element on a potentiometric sensors. In this work, a mimic receptor prepared by molecularly imprinting technique with (MAA or AM) as functional monomers and ethylene glycol dimethacrylate (EGDMA) as a cross linker, dispersed in PVC matrix plasticized with DOP solvent mediator was tested as a sensor for the determination of ACR. The sensors exhibit linear potentiometric response to $\mathrm{ACR}^{+}$ion with slope of $51.2 \pm 1.3\left(r^{2}=0.9993\right)$ and $50.5 \pm 1.4\left(r^{2}=0.9999\right) \mathrm{mV}$ decade $^{-1}$ and detection limits of $2.5 \times 10^{-7}$ and $8.7 \times 10^{-7} \mathrm{M}$ for sensors (I) and (II), respectively. Sensors (V) and (VI) based on NIPs exhibited no noticeable response. They revealed a potentiometric slope of $15.5 \pm 1.1$ and $16.3 \pm 0.7 \mathrm{mV}$ decade $^{-1}$ over the linear range $10^{-4}-10^{-3} \mathrm{M}$ with detection limits of $6.0 \times 10^{-5}$ and $6.5 \times 10^{-5} \mathrm{M}$ for sensors (V) and (VI), respectively. The potential response obtained with the sensors prepared with ACR-MIP or NIP membrane is given in Figure 6.

Table 2. Critical response characteristics of MIP based sensors plasticized with DOP under static mode of operation in $1.0 \times 10^{-2} \mathrm{M}$ phosphate buffer of $\mathrm{pH} 6.0$.

\begin{tabular}{ccccc}
\hline Parameters & $\begin{array}{c}\text { Sensor (I) } \\
\text { MIP/MAA }\end{array}$ & $\begin{array}{c}\text { Sensor (II) } \\
\text { MIP/AM }\end{array}$ & $\begin{array}{c}\text { Sensor (III) } \\
\text { MIP/MAA/TPB }\end{array}$ & $\begin{array}{c}\text { Sensor (IV) } \\
\text { MIP/AM/TPB }\end{array}$ \\
\hline Slope, (mV/decade) & $51.2 \pm 1.3$ & $50.5 \pm 1.4$ & $39.9 \pm 0.9$ & $41.0 \pm 1.6$ \\
Correlation coefficient, (r $\left.{ }^{2}\right)$ & 0.9997 & 0.9999 & 0.9998 & 0.9998 \\
Linear range, $(\mathrm{M})$ & $5.2 \times 10^{-6}-1.0 \times 10^{-3}$ & $5.2 \times 10^{-6}-1.0 \times 10^{-3}$ & $5.2 \times 10^{-6}-1.0 \times 10^{-3}$ & $5.2 \times 10^{-6}-1.0 \times 10^{-3}$ \\
Detection limit, (M) & $2.5 \times 10^{-7}$ & $8.7 \times 10^{-7}$ & $1.0 \times 10^{-6}$ & $8.9 \times 10^{-7}$ \\
Working range, $(\mathrm{pH})$ & $4.0-7.0$ & $3.5-7.0$ & $4.0-7.0$ & $3.5-7.0$ \\
Response time, $(\mathrm{s})$ & 10 & 10 & 10 & 10 \\
Life span, (week) & 8 & 8 & 8 & 8 \\
Standard deviation, $(\mathrm{mV})$ & 0.98 & 1.2 & 1.8 & 1.6 \\
\hline
\end{tabular}

The influence of $\mathrm{pH}$ on the potentiometric response of the MIP based sensors was examined with standard $10^{-4}$ and $10^{-3} \mathrm{M}$ ACR solutions over a $\mathrm{pH}$ range of $2-10$. The $\mathrm{pH}$ of the solution was adjusted with either hydrochloric acid and/or sodium hydroxide solutions. The sensors exhibited good stability over the $\mathrm{pH}$ range 4.0-7.0 and 3.5-7.0 for sensors (I) and (II), respectively. In this ranges, the percentage of ionization exceeds $99.9 \%$ for ACR that behaved as monovalent cation and this can be attributed to its pKa (9.29) [33]. All subsequence measurements were carried out in 0.01 phosphate buffer at $\mathrm{pH}(6.0)$. The $\mathrm{pH}$ profile of the proposed sensors show that at $\mathrm{pH}>7.0$ the potentials of the sensors declined with negative drift probably attributed to de-protonation of the drug molecules and formation of neutral aminoacridine species. 


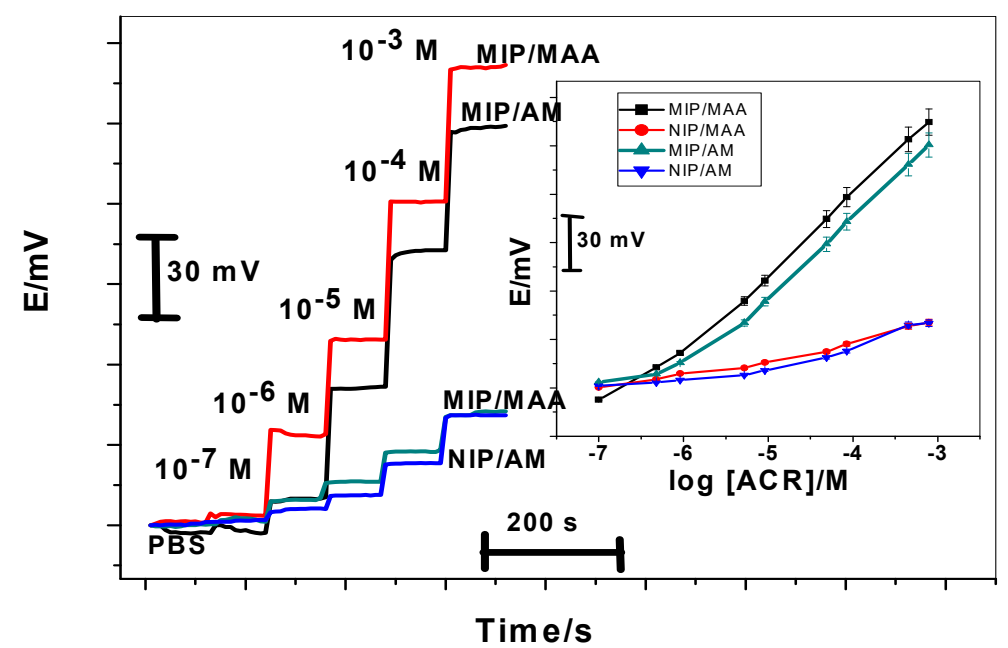

Figure 6. Response time and potentiometric response of aminoacridine (ACR) PVC membrane sensors based on molecularly imprinted polymers (MIPs) in $1 \times 10^{-2} \mathrm{M}$ phosphate buffer of $\mathrm{pH} 6.0$.

From industrial point of view, stability of MIPs are crucial, therefore life time of membranes was studied in this work [34]. The time required to obtain a steady potential response $( \pm 2 \mathrm{mV})$ using the proposed sensors in $1.0 \times 10^{-7}-1.0 \times 10^{-3} \mathrm{M}$ ACR solutions with a rapid 10-fold increase in drug concentration were $10 \mathrm{~s}$ for both sensors. After several calibrations for each sensor, low potential drift, long-term stability and negligible change in sensors response were observed. When not in use, the sensors were stored and conditioned in $10^{-2} \mathrm{M} \mathrm{ACR}$. All sensors examined exhibited good performance within reproducibility $\pm 3 \%$ for calibration slopes. The linear range and detection limits over a period of at least 8 weeks are reasonably stable. The long-term stability of the proposed sensors was evaluated by testing the sensors in different ACR concentrations $\left(10^{-4}\right.$ and $\left.10^{-3} \mathrm{M}\right)$ for 8 weeks. The sensitivity (slope of the calibration curve) was calculated according to three assay results each day. The variation of the slope of calibration plots is less than $3.0 \mathrm{mV}$ decade $\mathrm{e}^{-1}$ over $60 \mathrm{~d}$, thus showing a fairly good stability.

\subsection{Sensors Selectivity}

The selectivity behavior of ISEs is defined by the ion exchange constants which depend on the selectivity of complexation as well as on the standard free energies of the respective ions in the aqueous and organic phases [35]. Selectivity coefficients $\left(\log K^{p o t}{ }_{i, j}\right)$ of the sensors were determined using fixed interference method (FIM) with $1.0 \times 10^{-3} \mathrm{M}$ of the interfering in $0.01 \mathrm{~mol} \mathrm{~L}^{-1}$ phosphate buffer at $\mathrm{pH}$ 6.0. Both sensors exhibite no interference towards a range of organic copmounds as shown in Table 3. Sensors (I) and (II) displayed the same selectivity for hydroxylamine, 3-aminopyridine and hexamine but sensor (II) was more better in the presence of histidine, alanine, piperidine, dimethylamin and methylaminecompared with sensor (I). On the other hand, sensor (III) with TPB displayed better selectivity than sensor (II) for all the tested interferences while sensor (IV) with TPB displayed no improvement in the selectivity behavior.

\subsection{Hydrodynamic Monitoring of Aminoacridine}

A tubular-type detectors incorporating MIP/MAA and/or MIP/AM based membrane sensors were prepared and used under hydrodynamic mode of operation for continuous ACR determination. A linear relationship between the $\mathrm{ACR}^{+}$concentrations and FIA signals was obtained over a concentration range of $1.0 \times 10^{-5}$ to $1.0 \times 10^{-2} \mathrm{M}$ using a $1.0 \times 10^{-2} \mathrm{M}$ phosphate buffer of $\mathrm{pH} 6.0$ as a carrier solution and a flow rate of $3.5 \mathrm{~mL} / \mathrm{min}$. The general analytical features recorded under optimum flow conditions are presented in Table 4 . The sensors exhibit linear potentiometric response to $\mathrm{ACR}^{+}$ion with slopes of $51.0 \pm 0.3\left(r^{2}=0.998\right)$ and $50.7 \pm 0.2\left(r^{2}=0.998\right) \mathrm{mV} /$ decade and detection limits of $1.0 \times 10^{-6}$ and 
$1.0 \times 10^{-5} \mathrm{M}$. The sampling frequencies were about 22 and 18 samples per hour for sensors (I) and (II), respectively. Typical FI-diagrams for the sensors are shown in Figure 7A,B.
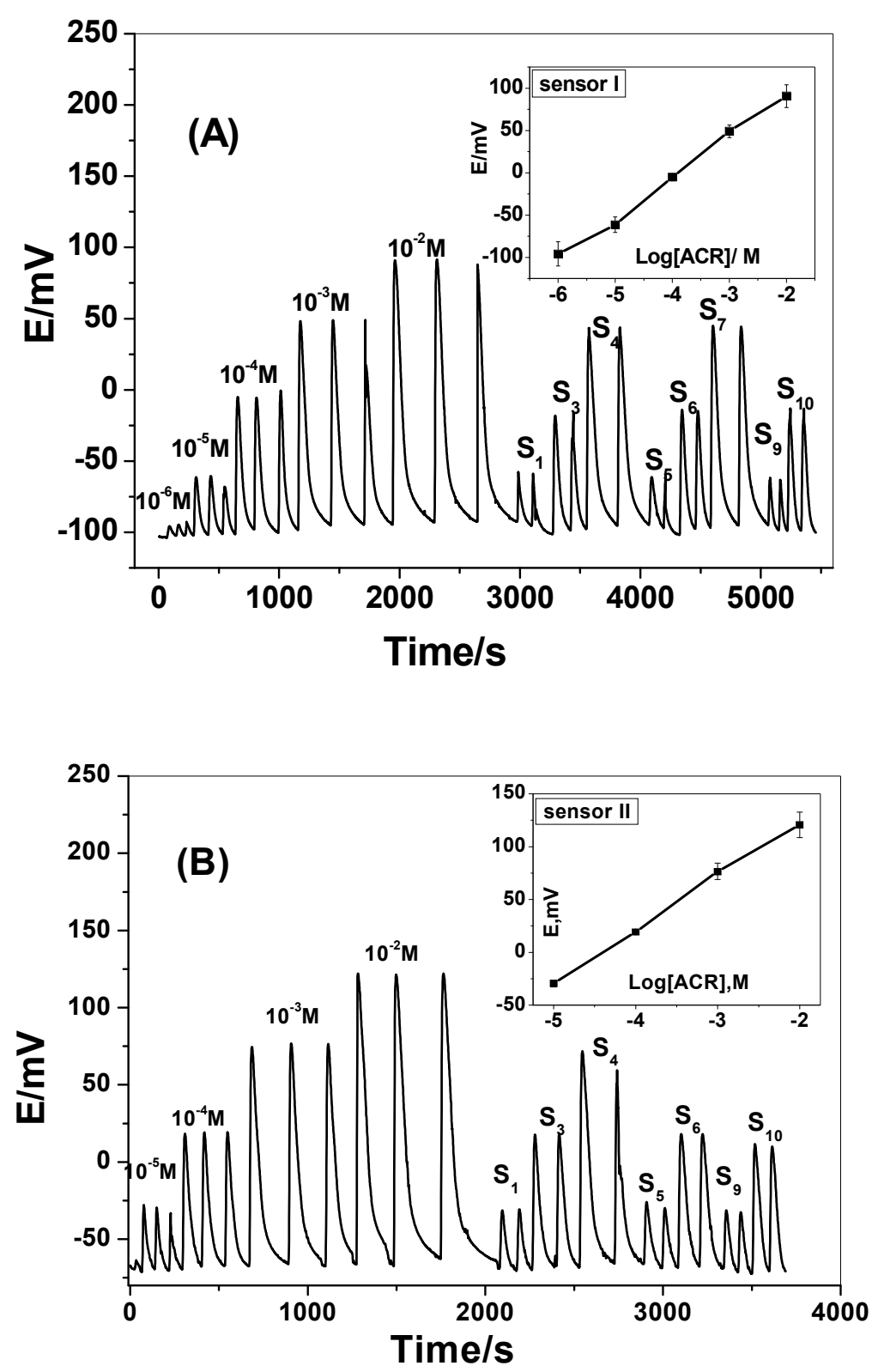

Figure 7. Transient potentiometric signals of MIP membrane based sensors plasticized with DOP. Conditions: carrier solution, $1 \times 10^{-2} \mathrm{M}$ phosphate buffer of $\mathrm{pH}$ 6.0; flow rate $3.5 \mathrm{~mL} / \mathrm{min}$; sample size $100 \mu$ L. (A) Sensor I; (B) Sensor II. 
Table 3. Potentiometric selectivity coefficients $\left(\log K^{p o t}{ }_{i, j}\right)$ of ACR membrane sensors plasticized with DOP in $1.0 \times 10^{-2} \mathrm{M}$ phosphate buffer of $\mathrm{pH} 6.0$.

\begin{tabular}{ccccc}
\hline Interfering Ion & \multicolumn{3}{c}{ Log $\mathbf{K}^{\text {pot }}{ }_{i, j}$} \\
\hline & Sensor (I) & Sensor(II) & Sensor (III) & Sensor (IV) \\
MIP/MAA & MIP/AM & MIP/MAA/TPB & MIP/AM/TPB \\
\hline ACR & 0 & 0 & 0 & 0 \\
Piperidine & -2.85 & -2.92 & -2.88 & -2.77 \\
Ethylendiamine & -2.73 & -2.86 & -2.86 & -2.89 \\
3-Aminopyidine & -2.90 & -2.93 & -3.00 & -2.89 \\
Hydroxylamine & -2.89 & -2.9 & -3.00 & -2.92 \\
Histidine & -2.80 & -2.94 & -3.05 & -2.95 \\
Alanine & -2.85 & -3.01 & -3.07 & -2.96 \\
Imidazole & -2.88 & -2.95 & -3.14 & -2.95 \\
Methylamine & -3.04 & -3.11 & -3.10 & -2.98 \\
Hexamine & -2.94 & -3.00 & -3.05 & -3.02 \\
Amprolium HCl & -2.71 & -2.86 & -3.30 & -3.04 \\
Urea & -2.87 & -2.98 & -3.10 & -3.04 \\
Dimethylamine & -2.90 & -3.06 & -2.86 & -3.10 \\
\hline
\end{tabular}

Table 4. Performance characteristics of ACR membrane sensors under hydrodynamic mode of operation in $1.0 \times 10^{-2} \mathrm{M}$ phosphate buffer of $\mathrm{pH} 6.0$.

\begin{tabular}{ccc}
\hline Parameters & Sensor (I) MIP/MAA & Sensor (II) MIP/AM \\
\hline Slope, $(\mathrm{mV} /$ decade) & $50.1 \pm 0.3$ & $50.7 \pm 0.2$ \\
Correlation coefficient, $\left(\mathrm{r}^{2}\right)$ & 0.9988 & 0.9988 \\
Linear range, $\mathrm{M}$ & $10^{-5}-10^{-2}$ & $10^{-5}-10^{-2}$ \\
Detection limit, $\mathrm{M}$ & $1.0 \times 10^{-6}$ & $1.0 \times 10^{-5}$ \\
Working range, $(\mathrm{pH})$ & $4.0-7.0$ & $3.5-7.0$ \\
Response time, $(\mathrm{s})$ & 10 & 10 \\
Life span, $($ week) & 8 & 8 \\
Flow rate, $\mathrm{mL} / \mathrm{min}$ & 3.5 & 3.5 \\
Sample rate/h & 18 & 22 \\
\hline
\end{tabular}

\subsection{The Analytical Applications}

Determination of $\left(\mathrm{ACR}^{+}\right)$in biological fluids was tested by spiking aliquots of human plasma or urine samples with a known concentration of standard $\mathrm{ACR}^{+}$in $1.0 \times 10^{-2} \mathrm{M}$ phosphate buffer of $\mathrm{pH}$ 6.0. The results of the added and found ACR are compatible with each other for all sensors with mean recovery between $93-105 \%$ for both static and hydrodynamic modes of operation. This confirms the applicability of the method for accurate routine analysis of ACR in biological fluids. In addition, the proposed method was used for $\mathrm{ACR}^{+}$assessment in pharmaceutical sample that currently available in local market (septogel). No interference was caused by active or inactive ingredients and diluents commonly used in the drug formulation. The results obtained on three batches (three determinations each) are shown in Table 5 for static and hydrodynamic mode of operation, respectively.

\section{Conclusions}

Static (manual) and hydrodynamic (FIA) mode of operations techniques are used to determine 9-aminoacridin (ACR) using molecularly imprinted polymers as new receptors in the polymeric membrane sensors. MAA and AM are used as functional monomers in the polymerization process. The simplicity in design, short measurement time, high analytical throughput, low limit of detection and good selectivity are advantages of these sensors. The recognition function of the imprinted polymer membrane towards the ACR is mainly attributed to the size of cavities formed. The sensors are used for determination of $\mathrm{ACR}^{+}$in human biological fluids and septogel drug. No interferences are 
caused by most ions that normally present in biological fluids or by the active or inactive ingredients and diluents commonly used in drug formulations.

Table 5. Determination of ACR in spiked plasma, urine and pharmaceutical samples using MIP membrane sensors under static and hydrodynamic modes of operation in $0.01 \mathrm{M}$ phosphate buffer of pH 6.0.

\begin{tabular}{|c|c|c|c|c|c|c|c|c|c|c|}
\hline \multirow{3}{*}{ Sample } & \multirow{3}{*}{$\begin{array}{l}\text { Added } \\
(\mu \mathrm{M})\end{array}$} & \multirow{3}{*}{$\begin{array}{c}\text { Labeled } \\
\text { (g) }\end{array}$} & \multicolumn{4}{|c|}{ Static Mode } & \multicolumn{4}{|c|}{ Hydrodynamic Mode } \\
\hline & & & \multicolumn{2}{|c|}{ Sensor (I) } & \multicolumn{2}{|c|}{ Sensor (II) } & \multicolumn{2}{|c|}{ Sensor (I) } & \multicolumn{2}{|c|}{ Sensor (II) } \\
\hline & & & Found & RSD $^{a}$ & Found & $\operatorname{RSD}^{a}$ & Found & RSD $^{a}$ & Found & RSD $^{a}$ \\
\hline S1 (Urine) & 10 & - & $10.2 \pm 0.04$ & $102.0 \pm 0.3$ & - & - & 9.78 & $97.8 \pm 0.4$ & 9.77 & $97.7 \pm 0.4$ \\
\hline S2 (Urine) & 50 & - & $50.3 \pm 0.02$ & $100.6 \pm 0.14$ & $51 \pm 0.6$ & $102.0 \pm 1.2$ & - & - & - & - \\
\hline S3 (Urine) & 100 & - & $99.8 \pm 0.01$ & $99.8 .1 \pm 0.7$ & $93.4 \pm 0.7$ & $93.4 \pm 1.3$ & 93.3 & $93.3 \pm 0.8$ & 95.5 & $95.5 \pm 0.8$ \\
\hline S4 (Urine) & 1000 & - & - & - & $906 \pm 0.5$ & $90.6 \pm 2.0$ & 990 & $99.0 \pm 0.5$ & 1040 & $104.0 \pm 0.5$ \\
\hline S5 (Plasma) & 10 & - & $10.2 \pm 0.06$ & $102.0 \pm 1.3$ & $10.5 \pm 1.4$ & $105 \pm 2.5$ & 9.64 & $96.4 \pm 0.4$ & 9.77 & $97.7 \pm 0.4$ \\
\hline S6 (Plasma) & 100 & - & $94.4 \pm 0.05$ & $94.44 \pm 2.0$ & $93.3 \pm 0.5$ & $93.3 \pm 1.2$ & 97.7 & $97.7 \pm 0.4$ & 95.5 & $95.5 \pm 0.4$ \\
\hline S7 (Plasma) & 1000 & - & $1090 \pm 0.01$ & $109 \pm 1.3$ & $934 \pm 0.4$ & $93.4 \pm 1.5$ & 1050 & $105.0 \pm 0.3$ & - & - \\
\hline S8 (Septogel) & - & 0.01 & $0.01058 \pm 0.01$ & $105.8 \pm 1.2$ & $0.00998 \pm 0.05$ & $99.8 \pm 1.8$ & 0.00987 & $98.7 \pm 0.1$ & 0.00972 & $97.2 \pm 0.3$ \\
\hline
\end{tabular}

Author Contributions: H.A.E.-N., A.H.K., and S.S.M.H. gave the concepts of the work, interoperated the results, the experimental part and prepared the manuscript. S.S.M.H. and A.H.K. cooperated in the preparation of the manuscript. S.S.M.H., A.H.K. and A.E.-G.E.A. performed the revision before submission. A.E.-G.E.A., M.E.-N. and N.M.K. revealed the financial support for the work. All authors read and approved the final manuscript.

Funding: This work is funded by King Saud University through Researchers Supporting Project (Project No. RSP-2019/66).

Acknowledgments: Authors are grateful to King Saud University for funding the work through Researchers Supporting Project (Project No. RSP-2019/66).

Conflicts of Interest: The authors declare no conflict of interest.

\section{References}

1. Gilman, A.G.; Goodman, L.S.; Gilman, A. (Eds.) Goodman and Gilman's the Pharmacological Basis of Therapeutics, 6th ed.; Macmillan Publishing Co., Inc.: New York, NY, USA, 1980; p. 980.

2. Osol, A.; Hoover, J.E. (Eds.) Remington's Pharmaceutical Sciences, 15th ed.; Mack Publishing Co.: Easton, PA, USA, 1975; p. 1102.

3. Schmitz, J.P. 9-aminoacridine-Its present status and current recommendations for use as a surgical and endodontic irrigant in dentistry. Oral Surg. Oral Med. Oral Pathol. 1980, 50, 273-276. [CrossRef]

4. Budavari, S. (Ed.) Medication (VET): Antiseptic. In The Merck Index-An Encyclopedia of Chemicals, Drugs, and Biologicals; Merck and Co., Inc.: Whitehouse Station, NJ, USA, 1996; p. 72.

5. Guerrero, R.O.S.; Icardo, M.C.; Gómez, C.; Benito, J.M. FIA-Chemiluminescence determination of acridine yellow. Anal. Lett. 2003, 36, 1039-1049. [CrossRef]

6. Naidu, P.R.; Krishnan, V.R. Determination of Acridine by Potentiometric Titration in Acetic Acid. Anal. Chem. 1961, 33, 497-498. [CrossRef]

7. Rao, K.C.M.; Naidu, P.R. Determination of acridine in Non-aqueous Media. Proc. Indian Acad. Sci. Sect. A 1972, 75, 86-91. [CrossRef]

8. Barek, J.; Matějka, J.; Zima, J. Determination of Acridine, Benz [c] acridine and Dibenz [a, h] acridine by Fast Scan Differential Pulse Voltammetry and Adsorptive Stripping Voltammetry. Collect. Czech. Chem. Commun. 1994, 59, 294-308. [CrossRef]

9. Bebawy, L.I.; Elghobashy, M.R.; Abbas, S.S.; Shokry, R.F. Chromatographic Determination of Aminoacridine Hydrochloride, Lidocaine Hydrochloride and Lidocaine Toxic Impurity in Oral Gel. J Chromatogr. Sci. 2015, 54, 492-499. [CrossRef]

10. Syed, A.A.; Silwadi, M.F.; Kirumakki, S.R.; Narasimiah, N. Gas chromatographic determination of residual acridine and iminodibenzyl in dibenzazepine drugs and related compounds. Acta Chromatogr. 2002, 12, 80-88.

11. Bunch, E.A. Pectrophotometric determination of aminacrinehydrochloridein creams, jellies, and suppositories: Interlaboratory study. J. Assoc. Off. Anal. Chem. 1987, 70, 560-565. 
12. Calatayud, J.M.; Sampedro, A.S.; Civera, P.V.; Benito, C.G. Spectrophotometrtc and fluorimetric determination of 9-amino acridine by flow injection analysis. Anal. Lett. 1990, 23, 2315-2325. [CrossRef]

13. Piletsky, S.A.; Alcock, S.; Turner, A.P. Molecular imprinting: At the edge of the third millennium. Trends Biotechnol. 2001, 19, 9-12. [CrossRef]

14. Mayes, A.G.; Mosbach, K. Molecularly imprinted polymers: Useful materials for analytical chemistry? TrAC Trends Anal. Chem. 1997, 16, 321-332. [CrossRef]

15. Haupt, K.; Mosbach, K. Molecularly Imprinted Polymers and Their Use in Biomimetic Sensors. Chem. Rev. 2000, 100, 2495-2504. [CrossRef] [PubMed]

16. Al-Kindy, S.; Badía, R.; Suárez-Rodríguez, J.L.; Díaz-García, M.E. Molecularly Imprinted Polymers and Optical Sensing Applications. Crit. Rev. Anal. Chem. 2000, 30, 291-309. [CrossRef]

17. Whitcombe, M.J.; Kirsch, N.; Nicholls, I.A. Molecular imprinting science and technology: A survey of the literature for the years 2004-2011. J. Mol. Recognit. 2014, 27, 297-401. [PubMed]

18. Kamel, A.H.; Al Hamid, F.A.; Soror, T.Y.; Galal, H.R.; El Gendy, F.A. Solid contact biosensor based on man-tailored polymers for acetylcholine detection: Application to acetycholinesterase assay. Eur. Chem. Bull. 2016, 5, 266-273.

19. Kamel, A.H.; Hassan, A.M.E. Solid Contact Potentiometric Sensors Based on Host-Tailored Molecularly Imprinted Polymers for Creatine Assessment. Int. J. Electrochem. Sci. 2016, 11, 8938-8949. [CrossRef]

20. El-Naby, E.H.; Kamel, A.H. Potential transducers based man-tailored biomimetic sensors for selective recognition of dextromethorphan as an antitussive drug. Mater. Sci. Eng. C 2015, 54, 217-224. [CrossRef]

21. Kamel, A.H.; Galal, H.R. MIP-Based Biomimetic Sensors for Static and Hydrodynamic Potentiometric Transduction of Sitagliptin in Biological fluids. Int. J. Electrochem. Sci. 2014, 9, 4361-4373.

22. Kamel, A.H.; Soror, T.Y.; Al-Romian, F.M. Graphite Solid-Contact Mepiquat Potentiometric Sensors Based on Molecularly Imprinted Polymers and Their Application to Flow Through Analysis. Anal. Methods 2012, 4, 3007-3012. [CrossRef]

23. Abd-Rabboh, H.S.M.; Kamel, A.H. Mimicking receptor for cyanide based on ion imprinting and their applications in potential transduction. Electroanalysis 2012, 24, 1409-1415. [CrossRef]

24. Kamel, A.H.; Mahmoud, W.H.; Mostafa, M.S. Biomimetic ciprofloxacin sensors made of molecularly imprinted network receptors for potential measurements. Anal. Methods 2011, 3, 957-964. [CrossRef]

25. Kamel, A.H.; Sayour, H.E.M. Miniaturized Potentiometric Sensors Based on Molecularly Imprinted Polymers for Flow-Through Assay of Quinine in Soft Drinks and Urine. Electroanalysis 2009, 21, 2701-2708. [CrossRef]

26. El-Kosasy, A.M.; Kamel, A.H.; Hussin, L.H.; Ayad, M.F.; Fares, N.V. Mimicking new receptors based on molecular imprinting and their application to potentiometric assessment of 2, 4-dichlorophenol as a food taint. Food Chem. 2018, 250, 188-196. [CrossRef] [PubMed]

27. Alvarez-Lorenzo, C.; Concheiro, A. Handbook of Molecularly Imprinted Polymers; Smithers Group Company: London, UK, 2013.

28. Hassan, S.S.M.; Elnemma, E.M.; Mahmoud, W.H.; Mohamed, A.H.K. Continuous Potentiometric monitoring of Sildenafil Citrate (Viagra) in Pharmaceutical Preparations using Novel membrane sensors. J. Appl. Electrochem. 2006, 36, 139-146. [CrossRef]

29. Sellergren, B. Molecularly Imprinted Polymers; Elsevier: Amsterdam, The Netherlands, 2001.

30. Buck, R.P.; Lindner, E. Recommendations for nomenclature of ion selective electrodes (IUPAC Recommendations 1994). Pure Appl. Chem. 1994, 66, 2527-2536. [CrossRef]

31. Nørby, J.G.; Ottolenghi, P.; Jensen, J. Scatchard plot: Common misinterpretation of binding experiments. Anal. Biochem. 1980, 102, 318-320. [CrossRef]

32. IUPAC. Recommendations for nomenclature of ion-selective electrodes. Pure Appl. Chem. 1976, 48, 129-132.

33. Goodell, J.R.; Svensson, B.; Ferguson, D.M. Spectrophotometric Determination and Computational Evaluation of the Rates of Hydrolysis of 9-Amino-Substituted Acridines. J. Chem. Inf. Model. 2006, 46, 876-883. [CrossRef]

34. Kupai, J.; Razali, M.; Buyuktiryaki, S.; Kecili, R.; Szekely, G. Long-term stability and reusability of molecularly imprinted polymers. Polym. Chem. 2017, 8, 666-673. [CrossRef]

35. Bakker, E.; Pretsch, E. Potentiometry at trace levels. Trends Anal. Chem. 2001, 20, 11-19. [CrossRef] 